\title{
CÂNCER DE PRÓSTATA: UM AGRAVO PARA A SAÚDE DO HOMEM
}

\section{ARTIGO ORIGINAL}

SOBRAL, Divanilda Leite de Almeida ${ }^{1}$

SOBRAL, Divanilda Leite de Almeida. Câncer de próstata: Um agravo para a saúde do homem. Revista Científica Multidisciplinar Núcleo do Conhecimento. Ano 05, Ed. 06, Vol. 11, pp. 102-113. Junho de 2020. ISSN: 2448-0959, Link de acesso: https://www.nucleodoconhecimento.com.br/saude/saude-do-homem

\section{RESUMO}

A presente pesquisa teve por objetivo apresentar o câncer de próstata e todos seus agravos para a população de modo geral, como também, mostrar o papel da enfermagem diante da situação, seja ela atuante na prevenção como na assistência a pacientes acometidos pela neoplasia. O estudo foi baseado através de revisões bibliográficas já concluídas, referentes aos anos de 2010 a 2015. Os métodos citados como tratamento para combater o câncer de próstata, como também os exames para rastreamento da doença, serão discutidos ao longo da revisão de literatura, da mesma forma, a importância que o enfermeiro desempenha na promoção da saúde dos homens, onde se encontra, muitas vezes, um público machista que não se importa constantemente em cuidar da saúde.

Descritores: Saúde do Homem, urologia, neoplasia da próstata, próstata, enfermagem e Câncer de Próstata.

\section{INTRODUÇÃO}

A pesquisa tem como objeto de estudo o agravamento do câncer de próstata nos brasileiros. O interesse em abordar o tema advém do fato de observar o quão citado tem sido este mal à saúde do homem pela mídia brasileira. $\mathrm{O}$ ato de prevenir a doença

${ }^{1}$ Pós-graduação em Oncologia e graduação em Enfermagem. 
tem sido bastante difundido pelas emissoras televisivas por constatar a incidência do câncer de próstata $(\mathrm{CaP})$ na população masculina.

Diante deste fato, surgem algumas indagações a respeito do tema que nos leva a investigar para poder compreender os porquês de ainda existirem homens que não fazem os exames específicos para prevenção da doença. Diante disto, esta pesquisa apresenta como objetivos específicos: O que significa estar com CaP atualmente? O que tem sido feito pela enfermagem para prevenir a doença?; porque alguns homens resistem em fazer os exames específicos para detecção da doença? E, Como a família pode ajudar na prevenção à doença?

De acordo com Damião et al (2015), o câncer de próstata está classificado em segundo lugar como o tipo de câncer que mais recorrente no mundo. Com relação ao Brasil, ele é o mais incidente, depois de tumores de pele não metanoma, com maiores índices nas regiões Sul e Sudeste.

Gansl; Arakelian e Brandão (2013) conceituam o termo câncer como sendo derivado da palavra grega karkinos (caranguejo) provavelmente por se apresentar semelhantemente como as garras desse crustáceo, ou seja, de modo que adere e se infiltra no corpo humano. São sintomas do câncer de próstata a dificuldade de urinar, retenção urinária, ardência ao uretral e polaciúria.

O que caracteriza um tumor maligno ou câncer, segundo Gansl; Arakelian e Brandão (2013), é a capacidade multiplicadora e desordenada que o mesmo desempenha no organismo, como também, a sua disseminação em alastrar-se para outras regiões do corpo humano.

Silva et al (2012, p. 362) afirmam que este tipo de câncer "atinge os homens a partir dos 40 anos e mais frequentemente acima dos 50 anos. É uma neoplasia que geralmente apresenta evolução lenta, de modo que a mortalidade poderá ser evitada quando o processo é diagnosticado e tratado com precocidade". 
Para Gansl, Arakelian e Brandão (2013), os cânceres não são hereditários, em sua maioria. Os que provém de questões genéticas são transmitidos, provavelmente, por alguns genes que são responsáveis por controlar a proliferação celular.

De acordo com o Instituto Nacional de Câncer - INCA (2013, p. 1), a idade é considerada o principal fator de risco para a doença. A neoplasia é considerada a doença da terceira idade, tendo em vista que cerca de três quartos acometem homens nesta faixa etária. "A maioria dos tumores cresce de forma tão lenta que não chega a dar sinais durante a vida e nem a ameaçar a saúde do homem".

A próstata, de acordo com Silva et al (2012), é uma glândula de exclusividade masculina, localizando-se na região inferior do abdômen, logo abaixo da bexiga e a frente do reto. É um órgão de tamanho pequeno, apresentando um formato de maçã. Envolve a porção inicial da uretra, canal pelo qual passa a urina para ser eliminada. A próstata é, também, responsável pela produção de parte do sêmen.

Vieira, Araújo e Vargas (2012), explanam que há diversas interferências para afastar o homem de realizar exames preventivos para o $\mathrm{CaP}$, tais como, constrangimento, falta de informações acerca da doença, medo e preconceito em realizar o exame do toque retal e da dosagem de Antígeno Específico Prostático (PSA). Exames esses que favorecem a detecção precoce da neoplasia e, assim, alcançar um possível sucesso.

Pesquisa do tipo bibliográfica que segundo Fonseca (2002) apud Gerhardt e Silveira (2009, p. 37), é "a pesquisa feita a partir do levantamento de referências teóricas já analisadas, e publicadas por meios escritos e eletrônicos, como livros, artigos científicos e páginas de web sites".

Segundo Gil (2010, p. 30), "a principal vantagem da pesquisa bibliográfica reside no fato de permitir ao investigador a cobertura de uma gama de fenômenos muito mais ampla do que aquela que poderia pesquisar diretamente".

Para responder a questão de pesquisa, realizou-se busca por acesso online na BVS - biblioteca virtual de saúde, utilizando os seguintes bancos de dados: Literatura 
Latino-Americana e do Caribe em Ciências da Saúde - LILACS, Medical Literature Analysis and Retrieval System Online - MEDLINE, Base de Dados Brasileiras de Enfermagem - BDEnf e Scientific Electronic Library Online - SCIELO.

Os artigos encontrados foram selecionados de modo que houvesse afinidade com os assuntos: câncer de próstata, neoplasia da próstata, urologia e saúde do homem.

Definiu-se como critérios de inclusão: artigos, teses e dissertações, que estivessem disponíveis na íntegra online. Como também, capítulos de livros que abordassem o tema da pesquisa. Publicados no idioma Português, no período de 2010 a 2016. Excluiu-se do estudo artigos que não respondam a questão da pesquisa, editoriais, relatos de casos informais, artigos que não disponibilizem o texto completo online e gratuito, que estejam fora do espaço temporal preconizado. A busca foi realizada no período de abril a maio de 2016.

\section{DESENVOLVIMENTO}

O CaP é o segundo tipo de câncer que acomete os homens no mundo, de acordo com Damião et al (2015), a idade é o único fator de risco determinado para que a doença se desenvolva. Ainda, de acordo com o mesmo autor, cerca de $62 \%$ dos casos diagnosticados ocorreram em homens com idade a partir dos 65 anos. Outros fatores de riscos que podem causar a o $\mathrm{CaP}$, são os aspectos étnicos e geográficos, onde a população negra é a mis acometida pela doença e a hereditariedade, apesar desta não ser considerada um fator prognóstico significativo.

De acordo com Damião et al (2015), pacientes que estão em fase inicial, onde podem ser curados, não desenvolverão sinais ou sintomas da neoplasia, diferentemente do estágio avançado da doença, onde os sinais e sintomas são aparentes.

Está no diagnóstico precoce e no rastreamento da doença em homens saudáveis, as maiores probabilidades de se erradicar do organismo masculino, a doença. De acordo com dados do INCA (2013), o rastreamento do CaP é importante para poder haver a redução da mortalidade pela doença, mas, por outro lado, realizar o rastreamento por 
dosagem de PSA em homens assintomáticos pode não trazer resultados benéficos, uma vez que o resultado poderá ser limitado. Para Silva (2012) a partir dos 40 anos de idade, é recomendável para o homem procurar o urologista anualmente e realizar os exames específicos para detecção do CaP, tais como: toque retal, sangue ou PSA e ultrassonografia.

A Fundação do Câncer (2015) aponta para o fato da informação sobre a doença CaP ser propagada, como também, realizar exames de rastreamento em homens cuja presença de câncer em sua família já tenha sido constatada.

Os exames de rastreamento para detecção ou não do $\mathrm{CaP}$, de acordo com Santos e Lamounier (2013), quando feitos em conjunto, são fundamentais para a credibilidade dos resultados. A. C. Camargo (2015), acredita que o PSA e o toque retal são considerados os mais eficazes para que a doença seja detectada 0 mais precocemente, caso haja foco da mesma.

O exame do toque retal, de acordo com o portal do instituto oncoguia (2014), consiste na introdução do dedo do médico, enluvado e com lubrificante, pelo reto do paciente com a finalidade de sentir a superfície da próstata. A próstata, por se localizar na frente do reto e pela maioria dos cânceres surgirem na região posterior da glândula, o toque retal torna-se importante para a detecção ou não da doença. Apesar de não ser um procedimento doloroso, a maioria dos homens não se sentem à vontade em realizar este exame. O toque retal é menos eficaz que o PSA, mas tem servido como exame de rastreamento da neoplasia, inclusive para detectar se o tumor poderá se espalhar para tecidos vizinhos.

Com relação ao PSA, o portal do instituto oncoguia (2014) diz que o antígeno prostático específico, é uma substância que se forma através das células prostáticas, tendo sua maior incidência no sêmen, e uma pequena quantidade no sangue. $O$ homem que apresenta nível de PSA de $4 \mathrm{ng} / \mathrm{ml}$ no sangue é considerado normal; quanto maior o nível de PSA no sangue mais chances da doença neoplásica se manifestar, mas o portal do instituto ainda relata que há incidência de homens neoplásicos apresentando níveis de PSA abaixo de $4 \mathrm{ng} / \mathrm{ml}$. Se o nível de PSA estiver 
elevado, o médico pode pedir uma biópsia para se certificar se há presença ou não do câncer.

Apesar dos autores citados serem a favor dos exames de rastreamento para detecção da neoplasia prostática, Andrade (2011), através de seus estudos, acredita que o PSA não pode ser considerado confiável plenamente, porque os próprios laboratórios de análises clínicas não têm exata certeza do valor considerado normal de PSA no organismo masculino. A falta desse conhecimento integral sobre a patologia, segundo Brasil (2008) apud Theobaldo, Girotti e Morbi (2014), sugere-se não praticar tal medida preventiva.

Apesar das controvérsias sobre a confiabilidade nos exames de rastreamento, o INCA (2014, p. 1), explana sobre o fato dos índices de CaP terem aumentado durante os anos no Brasil, o Instituto acredita que esses altos índices ocorrem devido ao "aumento da expectativa de vida da população, à melhoria da qualidade dos sistemas de informação, à maior disponibilidade dos métodos de diagnóstico e ao aumento do sobrediagnóstico", resultantes do rastreamento.

Saparavich e Canesqui (2013) citando Brasil (2008), afirma que a Política Nacional de Atenção Integral à Saúde do Homem (PNAISH), princípios e diretrizes, foi criada pela Secretaria de Atenção à Saúde, pertencente ao Ministério da Saúde, em agosto de 2008, 20 anos após o Sistema Único de Saúde (SUS) ter sido implementado no Brasil. É por conta da PNAISH, segundo Martins e Malamut (2013), que a saúde do homem brasileiro vem sendo discutida nos últimos anos.

Um dos princípios destacados é a necessidade de mudança da percepção masculina nos cuidados com a própria saúde e a dos seus familiares. Especificamente, o objetivo da política é organizar, implantar, qualificar e humanizar, em todo território brasileiro, a atenção integral à saúde do homem, dentro dos princípios que regem o SUS (SAPARAVICH E CANESQUI, 2013, p. 416). 
Ainda de acordo com Saparavich e Canesqui (2013), o objetivo do PNAISH é permitir que haja melhoras nas condições de saúde dos homens, e assim, reduzir os índices de morbimortalidade masculinos, de modo que eles, assim como as mulheres, tenham o cuidado com a saúde. Segundo os autores, a maioria dos homens procura assistência quando já estão acometidos pela doença.

A PNAISH evidencia que o público masculino tem os maiores índices de agravos na saúde em comparação com as mulheres e atribui isso, de acordo com Saparavich e Canesqui (2013), a fato de eles carregarem estereótipos culturais, de modo que, para Hermann e Caroline apud Silva et al (2015), o homem neoplásico não será afetado apenas na questão fisiológica, mas também no quesito cultural e emocional. Ou seja, afeta este homem que foi educado a ser viril, forte e corajoso, a descuidar da saúde acreditando que adoecer o tornaria fraco e covarde.

Ainda de acordo com Hermann e Caroline apud Silva et al (2015), quando se trata do $\mathrm{CaP}$, a doença ocupa uma posição bastante negligenciada, muitas vezes sendo tratada em estágios avançados, pelo fato de se localizar na região genital, região essa, símbolo de virilidade.

Couto e Gomes (2012) ao citar Brasil (2009), afirmam que os homens são mais suscetíveis a adoecer por terem dificuldades de cuidar mais de si mesmos, por acreditar que podem não adoecer. De acordo com os autores, a PNAISH é um importante instrumento para que a saúde do homem receba investimentos e apoio para poder estar sendo desconstruída a ideia de que o homem é viril e forte, e assim, não poder cuidar da saúde.

Vieira, Araújo e Vargas (2012) comentam que essas posições machistas nos homens os impedem de buscar ajuda médica constantemente, e no que se refere ao toque retal, para exame de rastreamento, a resistência fica ainda maior.

A radioterapia conformacional, segundo Lange (2013), é uma opção como tratamento para $\mathrm{CaP}$, desde que as doses diárias de radiação sejam ofertadas na medida que não atinja ainda mais a saúde do homem. A radiação deve ser emitida unicamente no 
tumor, para isso, os profissionais devem estar sempre se capacitando, a fim de não fragilizar ainda mais a saúde desse homem doente com a neoplasia.

Em conformidade com o autor citado no parágrafo anterior, os Institutos Oncoguia (2014) e o de Pesquisas Evolutivas (2015), sobre a forma de tratamento para o CaP, a radioterapia conformacional, será mais eficaz se utilizar a técnica por imagem, de modo que os profissionais seriam orientados até o tumor e, assim, não danificar os tecidos circunvizinhos. Cada tratamento deve levar em consideração diversas situações, como possíveis complicações, desconfortos e benefícios para o paciente.

A quimioterapia é outro método de tratamento que busca eliminar a neoplasia instalada no homem, da esma forma que a radioterapia Conformacional, ela deve ser aplicada paulatinamente, com intervalos entre as seções para que o organismo do paciente se fortaleça mais um pouco e possa receber outra dose de quimioterápico.

Guimarães (2014) apud Oliveira, Silvestre e Silva (2015), afirmam que no Brasil, cerca de 68 mil novos casos de $\mathrm{CaP}$ acometem a população masculina, isso remete ao fato de o diagnóstico precoce ser fundamental no combate à doença, tendo em vista que o tratamento é eficaz a medida que se descobre a patologia em seu início. À medida que não há a busca pela prevenção da doença, o tratamento torna-se dificultoso, acontecendo, muitas vezes, de ir ao médico quando a doença se encontra em estágio avançado ou metastático ao serem diagnosticado.

\section{PROFISSIONAIS DE ENFERMAGEM ATUANDO NA PROFILAXIA E NO TRATAMENTO DO CAP}

Os homens têm como aliados para prevenir o $\mathrm{CaP}$, de acordo com Theobaldo, Girotti e Morbi $(2014$, p. 2), "uma dieta rica em frutas, legumes, vegetais ricos em carotenoides (tomate e cenoura, por exemplo). [...] As vitaminas A, D, E, o selênio, licopeno, ômega 3, vitamina $\mathrm{C}$, naturalmente encontradas nos alimentos, possivelmente também possuem em efeito protetor". 
Ainda de acordo com os autores Theobaldo, Girotti e Morbi (2014) ao citar Brasil (2008), a equipe do Programa de Saúde da Família, também trabalham baseados em orientar a população através de hábitos de vida saudáveis; para isso, o enfermeiro, por exemplo, precisa estar capacitado para atender o público masculino e estar prestando orientações cabíveis no que diz respeito ao CaP.

A enfermagem, para Neri (2015), é uma profissão apta para poder cuidar da saúde do outro, apesar de não ser, frequentemente, uma profissão valorizada. É a profissão que pode atuar, segundo Fleming et al. (2011), na promoção e na prevenção da saúde para que haja a minimização da incidência da neoplasia na próstata. Para tal feito, a vigilância em saúde, uma grande aliada à equipe de saúde, precisa estar sendo realizada constantemente a fim de atingir os objetivos propostos.

Paiva, Motta e Griep (2011) apontam para o fato de a enfermagem ser diferenciada por se tratar de uma área da saúde que busca, exclusivamente, ser excelente na arte do cuidar, de modo como ver o ser humano de forma holística e não somente, a doença que acometeu o indivíduo. A enfermagem pode contribuir na orientação de homens neoplásicos através do plano de cuidados elaborado pelos profissionais da enfermagem, fazendo com que esses homens possam fazer parte de programas e receber os cuidados necessários para a promoção da saúde de maneira integral.

\section{CONSIDERAÇÕES FINAIS}

Por apresentar uma evolução lenta e silenciosa o câncer de próstata agrava a saúde do homem em diversos aspectos, inclusive no se estado de bem-estar. Toda a cultura masculina de que homem não sofre ou não chora, termina levando o público masculino a sofrer determinados problemas de saúde simplesmente por não buscar ajuda de profissionais que possam auxiliá-lo na manutenção de uma vida saudável.

Através das pesquisas feitas para poder compor este trabalho, foi possível perceber o quanto que a negligência da própria saúde pode fazer com que alguns homens cheguem a óbito. Não percebendo o agravamento da doença, o homem não nota o 
quão doente está, e assim, os cuidados prestados pela equipe de saúde se tornam mais difíceis, pois reverter um agravo não é, muitas vezes, de uma certeza absoluta.

É importante a equipe de saúde esteja em permanente aprendizado sobre a neoplasia para poder oferecer melhores condições de vida para o homem afetado pela doença e alcançar a cura almejada. Informações atualizadas acerca da doença contribuíram para este processo de bem-estar do paciente.

Não somente a equipe de saúde deve estar atenta a melhores meios para tratar o câncer, como também o homem e toda sociedade "machista", precisam desconstruir a ideia de que homem não chora ou não adoece, ou então, deixar de ser viril por ter adoecido.

\section{REFERÊNCIAS}

A. C. CAMARgo CANCER CENTER (org). Próstata: Fatores de risco. 2015. Disponível em: <http://www.accamargo.org.br/tudo-sobre-o-cancer/prostata/32/>. Acesso em: 02 de abril de 2015.

ANDRADE, Leonardo Fonseca de (portal). Diagnósticos \& tratamentos: PSA para câncer de próstata: mais para mito ou verdade? 2011. Disponível em: <http://www.drbayma.com/psapara-cancer-de-prostata-mais-para-mito-ou-verdade/>. Acesso em: 26 de abril de 2015.

COUTO. Marcia Thereza; GOMES. Romeu. Homens, saúde e politicas públicas: a equidade de gênero em questão. 2012. Disponível em: < http://www.arca.fiocruz.br/handle/icict/8842>. Acessado em 22 de maio de 2016.

DAMIÃO. Ronaldo, et al. Câncer de Próstata. Revista HUPE. Rio de Janeiro. 2015. Disponível em: $<$ http://www.epublicacoes.uerj.br/index.php/revistahupe/article/view/17931/13463>. Acessado em 18 de abril de 2016. 
FLEMING, N. L. F; SOUZA, R; DUARTE, D. A. Índice de Câncer de Próstata em uma Cidade de Pequeno Porte do Sul de Minas. Revista Eletrônica Acervo Saúde. v. 3. 145-146. 2011.

FUNDAÇÃO DO CÂNCER (org). Principais tipos: próstata. 2015. Disponível em: <http://cancer.org.br/sobre-o-cancer/tipos-de-cancer/prostata/>. Acesso em: 26 de março de 2016.

GANSL. Rene; ARAKELIAN. Renata; BRANDÃO. Císio. Medicina: mitos \& verdades. Oncologia. 8a edição. Ed. CIP. São Paulo 2013.

GERHARDT. Tatiana Engel; SILVEIRA. Denise Tolfo. Métodos de Pesquisas. 2009. Disponível em: < http://www.ufrgs.br/cursopgdr/downloadsserie/derad005.pdf>. Acessado em 01 de abril de 2016.

GIL. Antonio Carlos. Como elaborar Projetos de Pesquisa. 5a edição. Ed. Atlas. São Paulo. 2010

INCA. Rastreamento do Câncer de Próstata. 2013. Disponível em: < http://www1.inca.gov.br/inca/Arquivos/rastreamento_prostata_resumido.2013.pdf>. Acessado em 22 de maio de 2016.

INCA. Informativo Detecção Precoce. 2014. Disponível em: < http://www1.inca.gov.br/inca/Arquivos/Informativo_Deteccao_Precoce_2_agosto_20 14.pdf>. Acessado em 22 de maio de 2016.

INSTITUTO ONCOGUIA (org). Câncer de próstata: Biópsia para diagnóstico do câncer de próstata. 2014.2 Disponível em: $<$ http://www.oncoguia.org.br/conteudo/biopsia-paradiagnostico-do-cancer-de-prostata/1201/289/>. Acesso em: 08 de maio de 2016.

INSTITUTO ONCOGUIA (org). Câncer de próstata: Biópsia para diagnóstico do câncer de próstata.

2014.

Disponível em: 
http://www.oncoguia.org.br/conteudo/exame-de-toque-retal-para-diagnostico-docancer-de-prostata/5856/289/>. Acessado em 04 de junho de 2016.

INSTITUTO ONCOGUIA (org). Câncer de próstata: Biópsia para diagnóstico do câncer de próstata. 2014. Disponível em: < http://www.oncoguia.org.br/conteudo/antigeno-prostatico-especifico-psa-nodiagnostico-do-cancer-de-prostata/1202/289/>. Acessado em 04 de junho de 2016.

INSTITUTO DE PESQUISAS EVOLUTIVAS. IPE (org). Câncer de próstata: formas de tratamento. 2015. Disponível em: <http://ipe-instituto.org.br/index.php/saudeintegral/1249cancer-de-prostata-formas-de-tratamento $>$. Acesso em: 28 de maio de 2016.

LANGE, Richard Karl Uwe. (portal). Hospital Português. Radioterapia Conformacional. 2013.

$<$ http://www.hportugues.com.br/hospital/noticias/2003/fevereiro/radioterapiaconforma cional>. Acesso em: 01 de maio de 2016.

MARTINS. Alberto Mesaque; MALAMUT. Bernardo Salles. Análise do discurso da Política Nacional de Atenção Integral à Saúde do Homem. Revista Saúde e Sociedade. 2013. Disponível

em: <http://www.scielo.br/pdf/sausoc/v22n2/v22n2a14.pdf>. Acessado em 15 de maio de 2016.

MEDEIROS, A. P; MENEZES, M. F. B; NAPOLEÃO, A. A. Fatores de risco de prevenção ao câncer de próstata: subsídios de enfermagem. Rev. Bras. Enf. v.64, n.2, p. 385-8. mar/abr. 2011.

NERI, Manoel. (portal). Conselho Federal de Enfermagem - COFEM. Perfil da enfermagem: Após diagnóstico, COFEN cobra mudança. 2015. Disponível em: <http://www.cofen.gov.br/perfil-da-enfermagem-apos-diagnostico-cofen-cobramudancas2_31302.html>. Acesso em: 10 de maio de 2016. 
OLIVEIRA. Aldnéria Joaquina Rodrigues; SILVESTRE. Josimar Gonçalves Oliveira. SILVA. Dayane Camelo. A atuação da enfermagem frente às barreiras encontradas no diagnóstico precoce do câncer de próstata. 2015. Disponível em: $<$ http://fasem.edu.br/revista/index.php/fasemciencias/article/view/76/117>. Acessado em 10 de maio de 2016.

PAIVA, Elenir Pereira de; MOTTA, Maria Catarina Salvador da; GRIEP, Rosane Harter. Barreiras em relação aos exames de rastreamento do câncer de próstata. Revista LatinoAmericana de Enfermagem. São Paulo, v. 19, n.1, p. 1-8. 2011. Disponível em: <http://www.scielo.br/pdf/rlae/v19n1/pt_11.pdf>. Acesso em: 09 de abril de 2015.

SANTOS, Cinthia Lisbôa dos; LAMOUNIER, Thaís Alves da Costa. Aspectos clínicos e laboratoriais do câncer de próstata. Acta de Ciências e Saúde. Brasília, v.1, n.2. 2013. Disponível

em:

$<$ http://www.ls.edu.br/actacs/index.php/ACTA/article/view/52/59>. Acesso em: 02 de abril de 2015.

SEPARAVICH. Marco Antonio; CANESQUI. Ana Maria. Saúde do homem e masculinidades na Politica Nacional de Atenção Integral à Saúde do Homem: uma revisão bibliográfica. 2013.

Disponível em:

http://www.scielo.br/scielo.php?script=sci_arttext\&pid=S0104-12902013000200013>. Acessado em 15 de maio de 2016.

SILVA. Jaqueline da. Enfermeiro: teoria \& dica: questões de provas comentadas. Saúde do Homem. Rio de Janeiro. Editora Águia Dourada. 2012.

SILVA. Sílvio Éder Dias da, et al. Câncer - uma doença psicossocial: câncer no homem e a herança da cultura machista. 2015. Disponível em: < http://gestaoesaude.unb.br/index.php/gestaoesaude/article/view/695>. Acessado em 10 de maio de 2016.

SILVA. Roberto Carlos Lyra da, et al. Enfermeiro: teoria \& dicas: questões de provas comentadas. Rio de Janeiro. Editora Águia Dourada, 2012. 
THEOBALDO. Francine Machado; GIROTTI. Priscila Azevedo; MORBIO. Ana Paula Morbio. Atuação da enfermagem na prevenção do câncer de próstata. 2014. Disponível em:

http://fait.revista.inf.br/imagens_arquivos/arquivos_destaque/6cQOxsZUNoKiRaK_20 14-4-22-16-51-24.pdf>. Acessado em 02 de junho de 2016.

VIEIRA, Camila Guimarães; ARAUJO, Wilma de Sousa; VARGAS, Débora Regina Madruga de. O homem e o câncer de próstata: prováveis reações diante de um possível diagnóstico. Revista Científica do ITPAC. Araguaina, v.5, n.1, Jan. 2012. Disponível em: <http://www.itpac.br/arquivos/Revista/51/3.pdf>. Acesso em: 29 de março de 2015.

Enviado: Março, 2020.

Aprovado: Junho, 2020. 